\title{
Colors and Some Morphological Traits as Defensive Mechanisms in Anurans
}

\author{
Luís Felipe Toledo ${ }^{1}$ and Célio F. B. Haddad ${ }^{2}$ \\ ${ }^{1}$ Museu de Zoologia "Prof. Dr. Adão José Cardoso", Instituto de Biologia, Universidade Estadual de Campinas, \\ Rua Albert Einstein s/n, CP 6109, 13083-863 Campinas, SP, Brazil \\ ${ }^{2}$ Departamento de Zoologia, Instituto de Biociências, Universidade Estadual Paulista, CP 199, 13506-970 Rio Claro, SP, Brazil
}

Correspondence should be addressed to Luís Felipe Toledo, toledolf2@yahoo.com

Received 14 May 2008; Revised 22 October 2008; Accepted 16 December 2008

Recommended by Frank Seebacher

\begin{abstract}
Anurans may be brightly colored or completely cryptic. Generally, in the former situation, we are dealing with aposematism, and the latter is an example of camouflage. However, these are only simple views of what such colorations really mean and which defensive strategy is implied. For instance, a brightly colored frog may be part of a mimicry ring, which could be either Batesian, Müllerian, or Browerian. These are only examples of the diversity of color-usage systems as defensive strategies. Unfortunately, reports on the use of colors as defensive mechanisms are widespread in the available literature, and the possible functions are rarely mentioned. Therefore, we reviewed the literature and added new data to this subject. Then, we the use of colors (as defensive mechanism) into categories. Mimicry was divided into the subcategories camouflage, homotypy, and nondeceitful homotypy, and these groups were also subcategorized. Dissuasive coloration was divided into behavioral display of colors, polymorphism, and polyphenism. Aposematism was treated apart, but aposematic colorations may be present in other defensive strategies. Finally, we propose functions and forms of evolution for some color systems in post-metamorphic anurans and hope that this review can be the basis for future research, even on other animal groups.
\end{abstract}

Copyright ( $) 2009$ L. F. Toledo and C. F. B. Haddad. This is an open access article distributed under the Creative Commons Attribution License, which permits unrestricted use, distribution, and reproduction in any medium, provided the original work is properly cited.

\section{Introduction}

Anuran coloration results from natural selection acting simultaneously on different aspects of natural history, such as protection against solar radiation, thermoregulation, osmoregulation, nitrogen metabolism (e.g., [1-4]), reproductive biology (e.g., [5]), and defensive strategy (e.g., [6]).

Anurans are remarkable for their color patterns, which may range from a uniform black dorsum, as in Cycloramphus boraceiensis (Cycloramphidae), to bright blue, orange, red, yellow, and green in the same individual, as in Agalychnis callidryas (Hylidae). In the context of defensive strategies, these two distinct situations may be related to two different types of primary defenses, which operate regardless of whether or not a predator is in the vicinity [7]. Both situations: crypsis and aposematism, as generally understood, help anurans to survive in nature. The former may improve chances of avoiding detection, and the latter may signalize that the individual is dangerous in one or several ways, where being toxic is the most common [7]. Besides these, there are several other defensive strategies involving coloration, such as body rising, mimicry, or flash color (e.g., $[6,8,9])$.

The presence of these and other defensive colorations in anurans has been published for several species in a fragmented way, and has never been reviewed. Herein, in order to organize current knowledge and ground future research, we reviewed this subject, added new data, and provided information about the evolution of color usage in anurans, with special reference to Neotropical species.

\section{Materials and Methods}

We reviewed the literature by searching for colorationrelated defensive strategies in anurans. Both natural and experimental observations were considered. Additional data were obtained during several field expeditions in Brazil from 
1972 to 2007, mainly in the Cerrado and Atlantic Forest domains in the southeast.

All amphibian scientific names follow Frost [10], and the specific nomenclature for coloration categories was adapted from Pasteur [11]. It has been suggested that the terms "dupe" and "selective agent" be preferentially used instead of "predator," due to their broader meaning $[11,12]$. In other words, an anuran's coloration is not always selected or maintained to warn or avoid a predator; the "signal receiver" [13] may often be another anuran (e.g., in intraspecific communication) or their prey (i.e., the anuran may benefit from not being perceived by its prey). However, in the present paper, we choose to use "predator" to designate any animal that could be a potential risk to the anuran because we are analyzing coloration as a defensive strategy. For the same reason, we will not cover aggressive and reproductive mimicry in this paper.

\section{Results}

The use of colors can be divided into three major categories: mimicry, deceptive coloration, and aposematism (Table 1).

3.1. Mimicry. Mimicry is generally considered as per the Batesian mimicry concept, in which a nontoxic (or, otherwise, dangerous, e.g., the species may bite) species mimics a dangerous model species (generally toxic). However, Batesian mimicry is one of several types of mimicry into which anurans may be included (see Table 1). Mimicry (as presently defined) occurs when a group of organisms, the mimics, has evolved to share common perceived characteristics with another group of organisms, the models, through the selective action of a predator. Collectively, they are known as a mimicry complex. Mimicry was herein divided into three major groups: camouflage, homotypy, and nondeceitful homotypy (see what follows).

3.1.1. Camouflage. Camouflage may be defined as the resemblance of an animal with a part of the environment [7], especially as viewed by the predator at the time and place in which the prey is most vulnerable to predation (Endler [19]).

In post-metamorphic anurans, camouflage may be optical, chemical (e.g., production of floral, leaf-like, and ammonia odors), or acoustic (may occur, e.g., when frogs stop calling in the presence of a predator; e.g., [20]). In what follows, we will give special reference to optical camouflage, which implies avoidance of detection by possible predators.

(1) Eucrypsis. Definition: homochromy (imitation of reflected light) which is acting alone. The model is undefined, that is, it is the background.

(a) Visible Color Spectrum Mimesis. Many frogs are cryptic with the substrate they use, and there are a great variety of backgrounds and mimic frogs. As substrates, anurans may use rocks with lichens, tree trunks, leaves, forest litter, as well as mossy and rocky fields, for example. For any such substrates, there are mimic frogs that live there (Figure 1).
Eucrypsis may be strengthened or weakened by a predator's angle of vision; that is, the anuran may be more cryptic from a lateral view than from a dorsal view (Figures 1(f) and 1(e), resp.).

The more distant predator is from the site occupied by an anuran, the higher may be the crypsis benefits. For instance, it is easy to find a Dendropsophus nanus in its reproductive site when we are close to it. However, from a certain distance, the colors and shape of this hylid get mixed with the general view of the area. The size and colors of D. nanus are generally similar to part of the foliage, and it is hard to distinguish them from yellowish leaves (Figures 1(k), 1(l)).

(b) Nonvisible Color Spectrum Mimesis. Some studies have shown that several anuran species, from different families, may show a pronounced rise in reflectance in the infrared part of the spectrum (e.g., [21-23]). Furthermore, some predators of anurans, such as pit vipers, may be able to perceive infrared wavebands [24]. Others, such as rodents, other amphibians, lizards, and mainly birds, have tetrachromatic color vision (including ultraviolet cones), and may, therefore, perceive ultraviolet wavelengths (e.g., [25]). Therefore, it is possible that infrared reflectance may have evolved for anurans to remain cryptic in the foliage (which also has the same infrared reflectance property), even against those predators who are able to detect infrared or ultraviolet spectra (e.g., $[22,26])$.

(2) Mimesis. Definition: it is homomorphy (imitation of morphology) and/or homokinemy (imitation of movements), in addition to homochromy (defined before). The model is defined, that is, it is an object.

(a) Cryptic Mimesis. It holds when the model is a dominant element of the mimic's environment, such as green or brown leaves, sticks, rocks, lichens, and mosses. Many examples may be cited, but to mention some, we may refer to species of genera Proceratophrys and Scythrophrys which resemble fallen leaves (Figures 1(i), 1(j), resp.), as well as some species of Theloderma and Bokermannohyla that resemble mosses and lichens, respectively (Figure 1(b)).

The phyllomedusines of genus Phasmahyla, when walking, sway slightly as if caught by the movement of the wind (= homokinemy). Indeed, their genus name Phasmahyla was coined in allusion to the similarity of their moving style with the walking-sticks of order Phasmatodea [27]. The illusion created by this behavior is increased with the leaf-like color pattern of this species.

(b) Phaneric Mimesis. It holds when the model is an isolated and conspicuous inanimate element of the mimic's environment, such as animal droppings or rocks (when there are few rocks in the environment). As examples, we may cite some Theloderma spp. and Dendropsophus marmoratus, which resemble bird droppings, and many species of Rhinella and Bufo that resemble stones on the floor. 
TABLE 1: Major categories and subcategories of colors used as defensive strategies in post-metamorphic anurans.

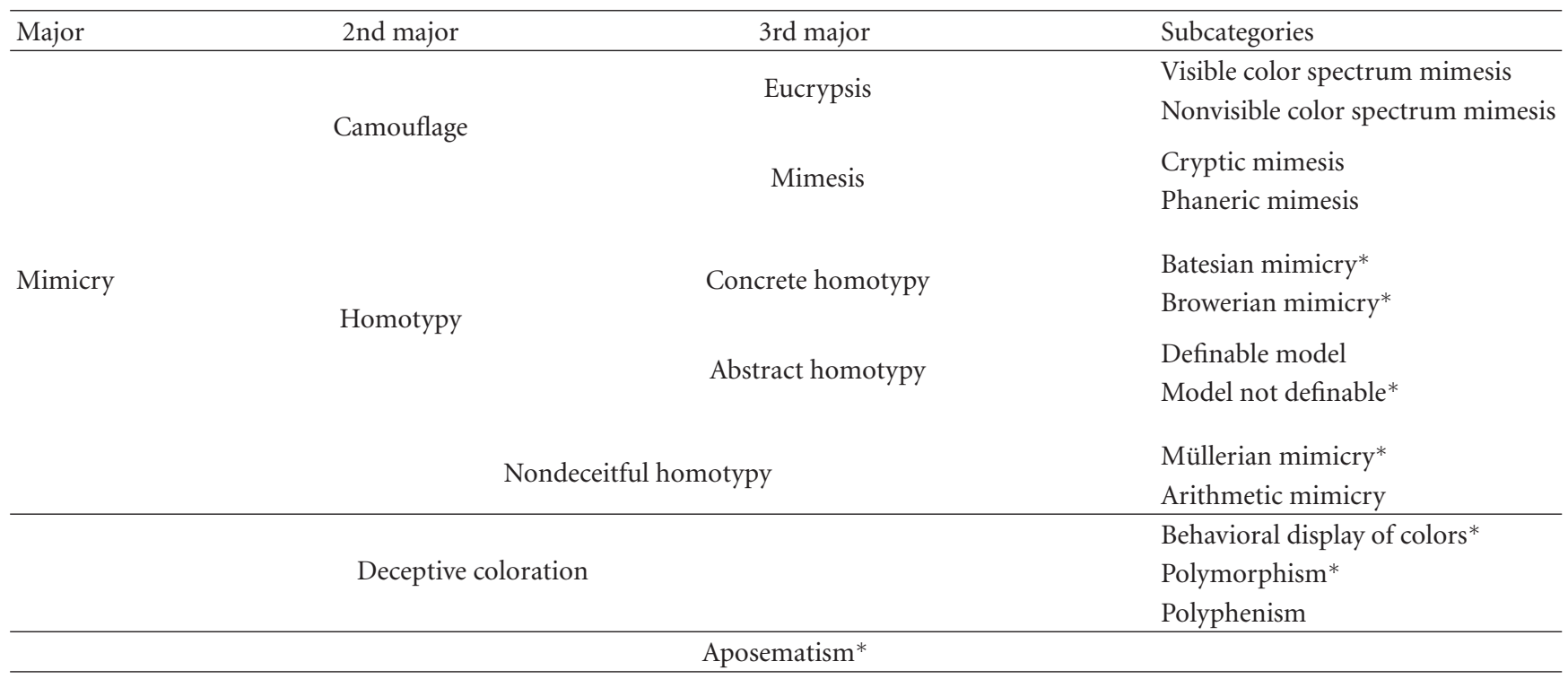

*Indication for where aposematic coloration may or must be present.

TABLE 2: Occurrence of Batesian and Müllerian mimicry in anurans, and distribution overlap between species.

\begin{tabular}{|c|c|c|c|c|}
\hline Mimic & Model & Mimetism type & Sympatric species & Source \\
\hline Aromobatidae & Dendrobatidae & & & \\
\hline Allobates zaparo & Ameerega bilinguis & Batesian & Yes & {$[14]$} \\
\hline Allobates zaparo & Ameerega parvula & Batesian & Yes & {$[14]$} \\
\hline Brachycephalidae & Dendrobatidae & & & \\
\hline Pristimantis gaigeae & Phyllobates lugubris & Batesian & Yes & {$[15]$} \\
\hline Pristimantis gaigeae & Phyllobates aurotaenia & Batesian & Yes & {$[15]$} \\
\hline Leptodactylidae & Aromobatidae & & & \\
\hline Leptodactylus lineatus** & Allobates femoralis** & Batesian & Yes & {$[16]$} \\
\hline Dendrobatidae & Dendrobatidae & & & \\
\hline Ranitomeya imitator & Ranitomeya fantasticus & Müllerian & Yes & {$[9]$} \\
\hline Ranitomeya imitator & Ranitomeya variabilis & Müllerian & Yes & {$[9]$} \\
\hline Ranitomeya imitator & Ranitomeya ventrimaculata & Müllerian & Yes & [9] \\
\hline Mantellidae & Mantellidae & & & \\
\hline Mantella laevigata* & Mantella manery* & Müllerian & Yes & {$[17]$} \\
\hline Mantella baroni ${ }^{*}$ & Mantella madagascariensis* & Müllerian & Yes & {$[17]$} \\
\hline Mantella pulchra* & Mantella cowanii* & Müllerian & Yes & {$[18]$} \\
\hline Dendrobatidae & Dendrobatidae & & & \\
\hline Phyllobates aurotaenia* & Phyllobates lugubris* & Müllerian & No & Present study \\
\hline
\end{tabular}

*In these cases, definition of the mimic and model is not possible.

** Further studies are needed in this case: see text.

TABLE 3: Characteristics, benefits acquired, and constraints involved in the evolution of different classes of anuran coloration.

\begin{tabular}{llll}
\hline Coloration classes & Main characteristic & Benefits acquired & Evolutionary constraints involved \\
\hline Cryptic coloration & Background matching & $\begin{array}{l}\text { Detection avoidance (by prey and } \\
\text { predators) }\end{array}$ & Predator and prey search image \\
\hline Aposematic coloration & Background contrasting & $\begin{array}{l}\text { Predator avoidance } \\
\text { Reproductive success }\end{array}$ & $\begin{array}{l}\text { Predator learning, presence of harmful } \\
\text { defenses*, sexual selection }\end{array}$ \\
\hline Deceptive coloration & Dissuasive coloration & $\begin{array}{l}\text { Predator avoidance } \\
\text { Reproductive success }\end{array}$ & Predator search image, sexual selection \\
\hline
\end{tabular}

* May be an exception in cases of Browerian and Batesian mimicry. 


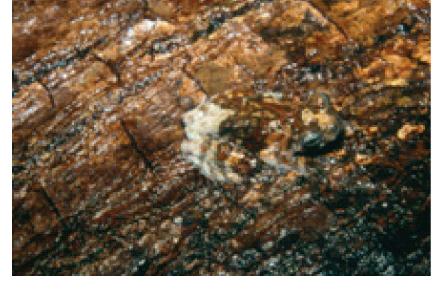

(a)

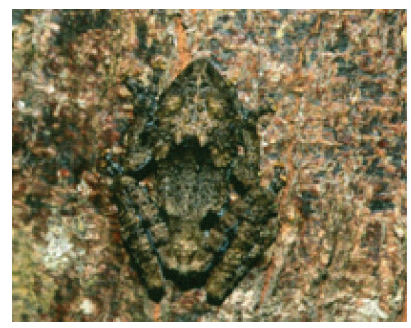

(e)

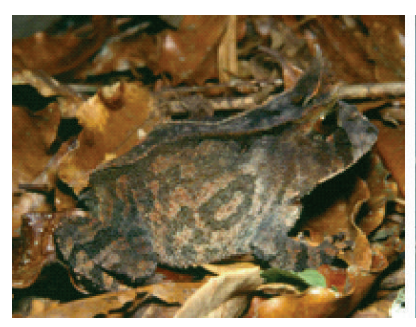

(i)

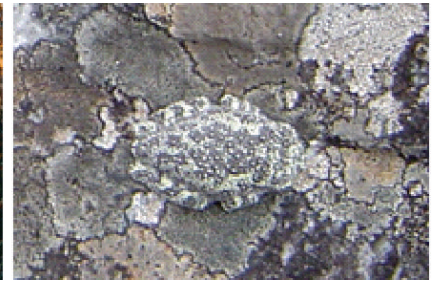

(b)

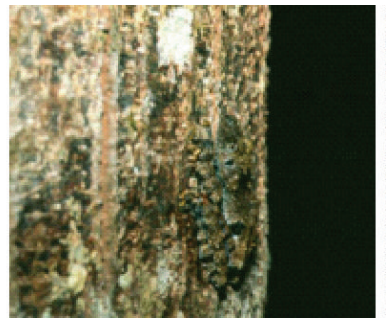

(f)

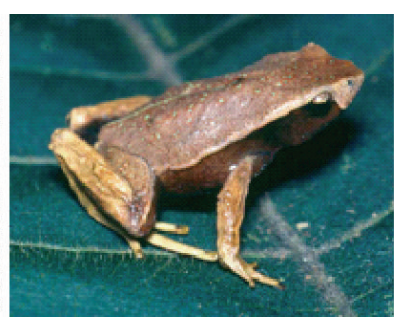

(j)

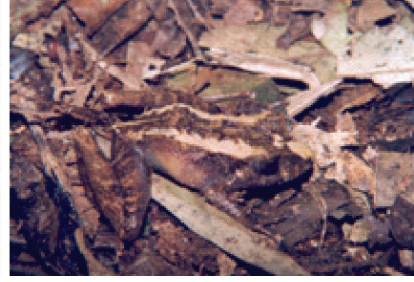

(c)

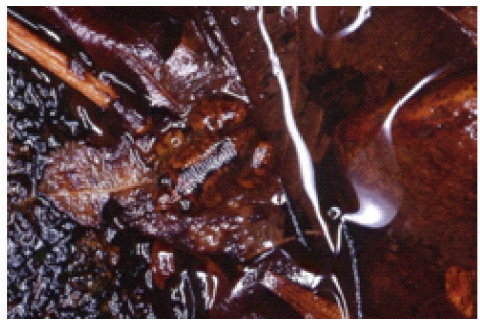

(g)

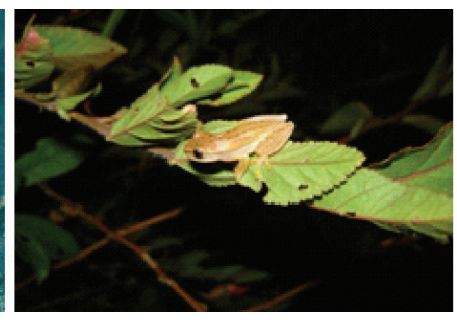

(k)

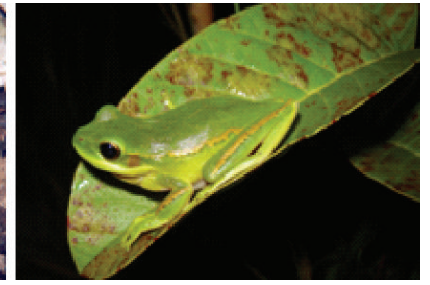

(d)

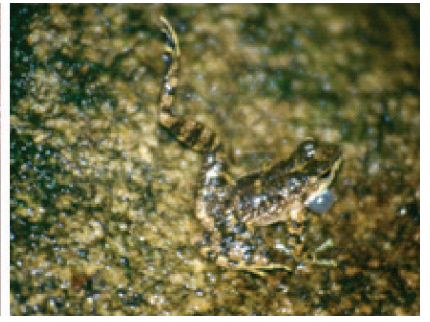

(h)

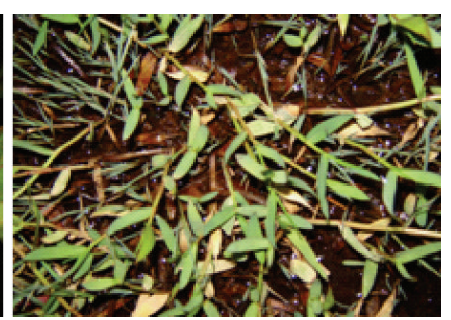

(1)

Figure 1: Different situations of cryptic mimicry in anurans: (a) Dendropsophus acreanus (Hylidae) on a tree trunk, (b) Bokermannohyla alvarengai (Hylidae) on a rock with lichens, (c) Ischnocnema guentheri (Brachycephalidae) on litter, (d) green morph of Hypsiboas prasinus (Hylidae) perched on a leaf, ((e)-(f), resp.) dorsal and lateral views of Theloderma horridum (Rhacophoridae) on a tree, (g) Lankanectes corrugatus (Nyctibatrachidae) in a lotic water body, (h) Hylodes asper (Hylodidae) on a wet rock, (i) Proceratophrys boiei (Cycloramphidae) on litter, (j) Scythrophrys sawayae (Leptodactylidae) on a dead leaf, (k) an adult male of Dendropsophus nanus (Hylidae) of practically the same size and shape as the leaves and (1) its reproductive site.

(3) Factors of Camouflage Enhancement. Both eucrypsis and mimesis imply camouflage, which could be strengthened by (a) countershading, (b) disruptive coloration, (c) shadow camouflage, (d) wetting, and (e) integumentary structures.

(a) Countershading. Countershading occurs when the anuran's pigmentation is darker dorsally and lighter ventrally. This transition may be gradual or abrupt, which could involve different camouflage strategies (see $[28,29]$ ).

Two main functions have been attributed to countershading. (i) it is believed to have the effect of reducing conspicuous shadows cast on the ventral region of an animal's body. In essence, the distribution of light on objects lit from above will cause unequal reflection of light by a solid body of uniform color. Such shadows could provide predators with visual cues to a prey's shape and projection. Countershading, therefore, reduces the ease with which prey is detected by potential predators by counterbalancing the effects of shadowing. This effect occurs mainly in animals that present a gradual transition of colors [28], and should be properly named "self-shadow concealment" [29]. (ii)
Countershading coloration would work via background matching; that is, when seen from the top, the dorsum (if cryptic colored) blends into the background below, which could be a body of water (when the anuran is swimming or floating) or dry-to-flooded ground (when the anuran is on the floor or perched in the vegetation). When seen from below, the lighter ventral area blends into the sun or moonlight (see [29]). This second explanation generally occurs with an abrupt transition of colors and seems to be the more adequate for anurans.

Countershading could result from selective pressures other than predation avoidance. For example, the dorsal surface must be protected against the damaging properties of UV light and/or abrasion Kiltie [30, 31], and the ventral side does not need to be pigmented, as pigmentation may be costly [29]. Therefore, the occurrence of countershading may result from multiple factors.

This system is so widespread among aquatic and terrestrial fauna that several authors have stated that it is perhaps the most universal feature of animal coloration (see [29] and references therein). Likewise, it is present in several anuran species and might work against terrestrial predators, 
for example, which may be on the ground when the anuran is perched on a tree branch. In aquatic species, such as the pipids (e.g., Pipa spp. and Xenopus spp.), the system may work as described for fishes.

(b) Disruptive Coloration. Disruptive coloration is a color pattern that breaks the appearance of body form. Several anuran species have dorsal lines and/or blotches that may be considered constitutive of disruptive coloration, breaking the general outline of the body. Some species may enhance their camouflage by having high-contrast lines on the edges of colored patterns (see [32]). In addition to this, several species present lateral lines that cross the eyes, breaking their rounded shape (Figure $1(j))$. These are the most common forms of disruptive coloration in anurans.

A possible variation is the presence of aposematic coloration (see what follows for an explanation of aposematism) simultaneously with disruptive coloration, depending on the predator and/or brightness of the night. This may occur because the colorful stripes and/or blotches of an aposematic anuran (Figure 2(a)) may become a disruptive pattern when seen by a color-blind predator, or by a color vision predator hunting on dark nights (Figure 2(b); see also [33, 34]).

Recently, it has been suggested and/or demonstrated that disruptive coloration is advantageous compared to simple eucrypsis (see $[35,36]$, and references therein).

(c) Shadow Camouflage. Anurans may rest in areas with combined spots of sunlight and shade, making it difficult to recognize the animals on the substrate. If part of the anuran is exposed to sunlight and the other part is in shadow, such light play may enhance the anuran's disruptive pattern (e.g., [32]).

(d) Wetting. Some individuals may remain in lotic water bodies, covered by a film of water or by water drops. This situation may enhance an animal's crypsis against terrestrial predators, by creating reflected shiny spots on its dorsum matching the shiny spots in the water or substrate, for example, rocks (Figures $1(\mathrm{~g})-1(\mathrm{~h})$ ).

(e) Integumentary Structures. Some integumentary structures seem to be associated with disruptive outlines and thereby aid in concealment. Such structures include small, irregular ridges, supraciliary processes (e.g., species of Proceratophrys and Ceratophrys), scalloped folds on the outer edges of limbs (e.g., Cruziohyla craspedopus), and calcars (e.g., several Hypsiboas spp.). Dorsal glands may also enhance crypsis by promoting resemblance with lichens (e.g., Bokermannohyla alvarengai, Itapotihyla langsdorffii, and Scinax nebulosus) or mosses (e.g., Theloderma corticale and other Vietnamese mossy frogs) (Figure 1).

3.1.2. Homotypy (Assimilation to Another Type). It acts differently from camouflage: in homotypy animals can be perceived by the predator. Homotypy involves the mimetic imitation of another object (which can be the same or another species, an object of the environment, or an undefined model), being, therefore, included as mimicry.

(1) Concrete Homotypy (Actual Model). The model is definite or an existing species (or cluster of similar species).

(a) Batesian Mimicry. The concept of Batesian mimicry [37] involves the success of a specific coloration against a predator's experience; that is, predators learn to avoid unpalatable species, which are identified by their aposematic coloration (which does not always mean bright colors: e.g., $[11,38])$, odor, sound, or another signal. Thus, a mimic could obtain protection by resembling the unpalatable or less palatable model. For anurans, there are few cases described wherein some palatable frogs may mimic some poison frogs (Table 2).

Batesian mimicry involves the predator's ability to learn or have innate knowledge. Several predators, such as invertebrates in general, are not as well-endowed in terms of sight and memory as are mammals, and, therefore, may not have been the promoters of selective pressures for the evolution and persistence of Batesian mimicry (see also [11]).

A Batesian mimic does not necessarily need to be identical to its model. Sometimes, it may exhibit intermediate resemblances to two (or more) models. In this manner, the mimic may escape from some predators that avoid one model and from others that avoid the other model. This dual mimicry system has been proposed for coral snake mimics [39] and may be present in anurans.

An intriguing situation is the Batesian mimicry proposed for the Leptodactylus lineatus and Allobates femoralis complex. This complex would actually represent a case of Müllerian mimicry (where both species are unpalatable; see further explanations below), instead of Batesian mimicry as initially proposed [16], as L. lineatus seems to be a noxious species as well. Upon handling and fixing individuals of L. lineatus, they exude a great amount of milky, probably noxious secretions (C. F. B. Haddad, personal observation). However, some tests performed on A. femoralis indicated that this species is not toxic (see [40], and references therein). If $A$. femoralis is not toxic and L. lineatus is, this would be once again a case of Batesian mimicry where L. lineatus is the model. If both species are discovered to be nontoxic, it would be a case of Arithmetic mimicry (where both species are palatable; see further explanations below). Therefore, the relationship of this complex remains unresolved and requires further research.

(b) Browerian Mimicry. When individuals within a species differ in palatability to predators, the more palatable individuals (mimics) will gain benefits from those less palatable (models). The models can be of the same or opposite sex to the mimics. Albeit never reported that this type of mimicry may be present in aromobatids, bufonids, dendrobatids, mantellids, and myobatrachids, at least. Individuals of the same noxious species of these families (cited above) acquire the alkaloids contained in their noxious secretions from dietary arthropods (e.g., [41-43], and references therein). 


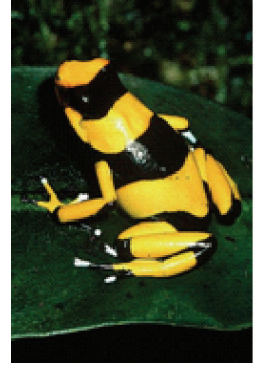

(a)

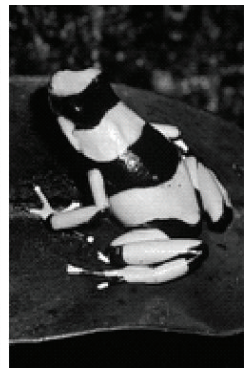

(b)

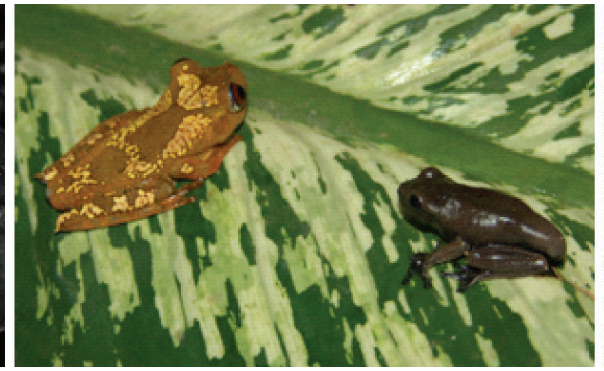

(c)

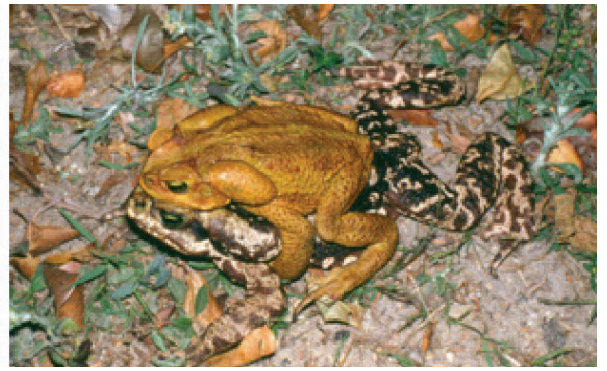

(d)

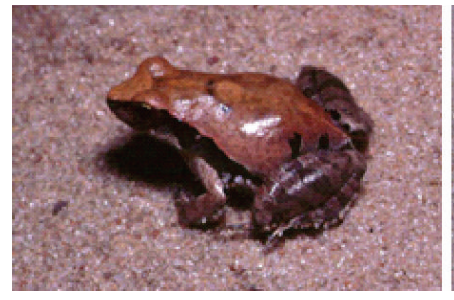

(e)

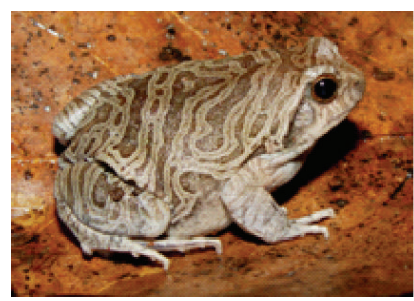

(i)

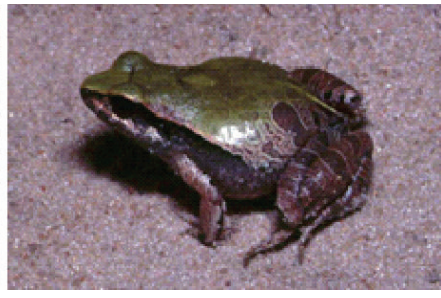

(f)

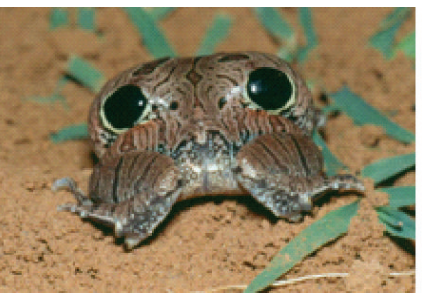

(j)

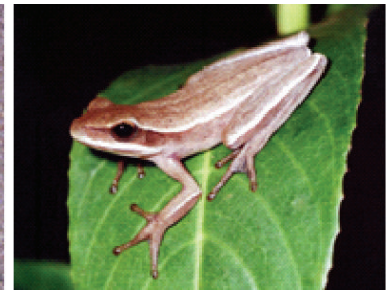

(g)

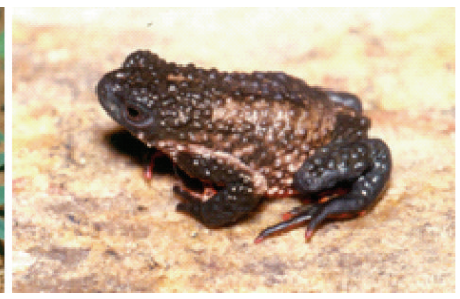

(k)

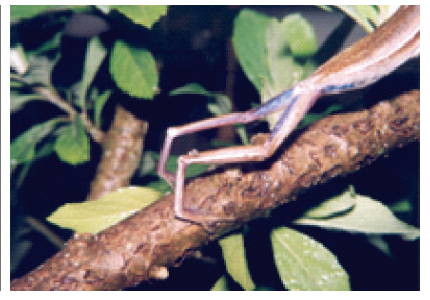

(h)

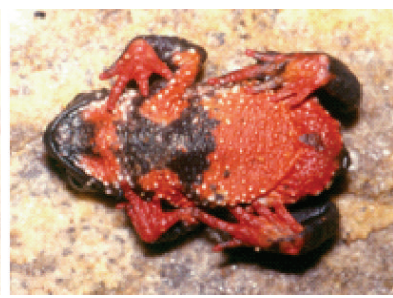

(1)

Figure 2: (a) An aposematic Oophaga lehmanni (Dendrobatidae) (b) may have disruptive coloration on dark nights or when searched for by a color-blind predator. (c) An adult and a juvenile Hypsiboas semilineatus (Hylidae), (d) an amplectant pair of Rhinella icterica (Bufonidae), and ((e)-(f)) two morphs of Physalaemus cuvieri (Leiuperidae) are examples of polyphenism. ((g)-(h)) Flash color exhibited by Hypsiboas caingua (Hylidae), ((i)-(j)) deimatic behavior by Eupemphix nattereri (Leiuperidae), and ((k)-(l)) thanatosis by Melanophryniscus moreirae (Bufonidae).

Therefore, if for any reason a group of individuals within a species either does not feed on arthropods that carry the alkaloids, feeds on them but at a lower rate/proportion, or does not sequester these components, they will be less poisonous than the others (e.g., [44-47]).

Indeed, there are reports that show spatial (geographic) and temporal (seasonal) variation in the alkaloid profiles of poison frogs [48], which may support the Browerian mimicry theory for anurans.

(2) Abstract Homotypy (Virtual Model). When the model is not an actual species, homotypy is an abstract.

(a) Definable Model. It occurs when the model looks like a general type of organism, or part or indirect vestiges of another organism, but is not identifiable at species level. For example, the deimatic eyespots present on the back of leiuperids, which could resemble snakes' eyes (see, e.g., [6]), but not of a specific species of snake. Other examples are frogs that rest on leaves and look like bird droppings (e.g., Dendropsophus marmoratus and Theloderma spp.). Besides this, the presence of calcars on many species of rainforest tree frogs, and their absence in other anurans, may suggest that they might serve as points of water runoff, mimicking drip tips of leaves [49, page 371].

(b) Model Not Definable. Occurs when the model is not identifiable at all, but a frightening or cryptic form is conjured up. This seems to be the case for the leg interweaving behavior described elsewhere (see [50]).

3.1.3. Nondeceitful Homotypy. This category was created (sensu [11]) basically for the inclusion of Müllerian mimicry [51, 52] and Arithmetic mimicry [53]. In both cases, the predator is not deceived, that is, the predator can recognize whether the anuran is palatable or unpalatable. In this category, both the model and the mimic are either unpalatable and/or dangerous in some way (Müllerian mimicry), or palatable (arithmetic mimicry).

These mimicry complexes are formed by species with similar (or even exactly the same) color pattern. However, it is sometimes hard to distinguish real nondeceitful homotypy from a possible phylogenetic influence; that is, closely related species, such as two species of Dendrobates, may resemble 
one another due to a simplesiomorphy (sharing of an ancestral character) and not because of coloration convergence (homoplasy). Whether a convergence or a simplesiomorphy, the resemblance would benefit the two (or more) species involved.

(a) Müllerian Mimicry. Müllerian mimicry involves the mutual benefit of two dangerous (e.g., toxic, noxious, unpalatable, able to harm the aggressor by any means, such as biting and scratching, etc.) species by sharing similar phenotypes [51, 52]. To our knowledge, there are only few cases of Müllerian mimicry in anurans (see Table 2); however, other possible mimicry relationships may be suggested based on the current reports. We may join two mimicry complexes of Mantella (M. baroni/madagascariensis and M. pulchra/cowanii) into a larger group of mimicry species, as all individuals are sympatric and exhibit homochromy and homomorphy $[17,18]$. Furthermore, from the evidence of Batesian mimicry by Pristimantis gaigeae with both Phyllobates aurotaenia and P. lugubris as models, we may suggest another Müllerian mimicry system. This system would be comprised of $P$. aurotaenia and $P$. lugubris. These two species are not sympatric, however, chronosympatry (presence of model and mimic in the same time and place) is not a rule for the existence of mimicry $[54,55]$; for instance, their past distributions could have overlapped (see also [15]), and/or the present distribution of selective agents (predators) may overlap with the distribution of both species (including Batesian mimic P. gaigeae).

Furthermore, it is possible that other Müllerian mimicry systems exist that are not based on coloration but still comprise visual mimetism. For example, if two differentcolored species, or different morphs of the same species, present the same toxic substances, they could be chemical mimics. Therefore, based on properties other than color, such as body shape and brightness, they could be part of a Müllerian mimicry ring (see also [56]). This would partly explain the several cases of polymorphism among aposematic species (see below).

(b) Arithmetic Mimicry. Similar sympatric edible species share the burden of predation in proportion to their relative frequencies. In other words, the higher the abundance of a certain (color) morph in the predator foraging area, the lower the chances of an individual prey being preyed upon. In this case, predator learning (ontogenetic or inherited) is irrelevant. To our knowledge, arithmetic mimicry has never been reported for anurans; however, it may be a very widespread phenomenon involving several sympatric (or even syntopic) similar (e.g., in simultaneous homochromy, homomorphy, and homokinemy) species. As examples of species pairs (or more), there are syntopic Leptodactylus furnarius and L. jolyi; Dendropsophus nanus, D. sanborni, and D. minutus; Proceratophrys appendiculata, $P$. boiei, and $P$. melanopogon; as well as several species of Ischnocnema, all of them found chronosympatrically in the Neotropical region.

Furthermore, two species with differences in coloration (for instance), but of similar sizes (for instance), may also be arithmetic mimics. Both of these edible species sharing a predator foraging area may be equally nutritive; therefore, provided that the predator can perceive that they are both nutritive, they will be nutritional arithmetic mimics, benefited by the saturating theory (see [56]).

\subsection{Deceptive Coloration}

3.2.1. Behavioral Display of Colors. Many anurans may exhibit deceptive coloration, either intentionally or not, by performing movements (e.g., flash color behavior) or by adopting specific postures (e.g., body raising).

A fleeing anuran may escape from predators by displaying a flash of aposematic color(s), generally followed by remaining motionless. This is known as flash color behavior. This coloration is only visible when the anuran is moving (generally while jumping), and concealed during resting posture (Figures $2(\mathrm{~g})-2(\mathrm{~h})$ ). Flash color is widespread among anurans, occurring in several species and families. In the Neotropics, it is very common in species of genera Scinax and Hypsiboas (Hylidae).

Flash color behavior may serve to disorientate and confuse an attacking predator [7] and/or warn predators of the presence of toxins [57]. These two distinct functions, and the implied predator responses, may vary among individuals or species of predator. In other words, some predators may be warned, while some may get confused. In this latter case, the predator may lose the anuran: the flash behavior may precede the motionless behavior, creating a prey search image that quickly disappears $[7,58]$. Also, flash color behavior may halt the predator's attack for an instant and, thus, provide extra time for the frog to escape [59].

Another possibility of color display is body raising. For example, in some leiuperids (e.g., Eupemphix nattereri, Physalaemus deimaticus, and Pleurodema brachyops), when individuals lift their hindparts, they exhibit a pair of black eyespots (Figures 2(i)-2(j)). Similarly to flash color behavior, this exhibition may be viewed as an aposematic signal (as these species have large poison glands below the eye-spots) or may be a deceptive signal. In this latter case, the predator may have the illusion of facing a different (and larger) animal. Therefore, it would be better classified as an abstract homotypy where the model is definable (see above).

3.2.2. Polymorphism. Polymorphism in anurans is characterized by the presence of fixed chromatic phenotypes within or between populations. The individuals seem unable to change their color, so there must be genetic control involved. Polymorphism may benefit the anuran in such a way that one or more of the phenotypes are not included in the predator's search image. Several species are known to present different chromatic morphotypes, and such polymorphism may occur in three ways as follows.

(a) Between Individuals, Independent of Sex and Life Stage. Two morphotypes: for example, some adult individuals of Physalaemus cuvieri (Leiuperidae) and Paratelmatobius spp. (Leptodactylidae) are green, while others are brown 
(Figures 2(e)-2(f)). Another type of color dimorphism is exhibited by individuals of Leptodactylus fuscus (Leptodactylidae), which may or may not have a dorso-vertebral white line.

More than two morphotypes: several species of cryptic genera Eleutherodactylus and Ischnocnema (Brachycephalidae) exhibit many different color morphotypes [60]. Even in aposematic species, this sort of polymorphism can also be observed; for example, in Anomaloglossus beebei (Aromobatidae), there are five color morphotypes [61], and in Oophaga pumilio (Dendrobatidae), there are at least 15 color morphotypes (see, e.g., [5, 23]). Multiple aposematic phenotypes are also observed in other dendrobatids [62] and African mantellids (see, e.g., [63]). Multiple aposematic phenotypes may add the benefits of aposematism to the benefit regarding predator search image (see before).

(b) Between Life Stages: Juveniles Different from Adults. This is the case of Hypsiboas geographicus, $H$. semilineatus, $H$. lundii, $H$. pardalis, and $H$. raniceps (Hylidae), for instance, where juveniles have a totally different coloration from adults, independent of sex (Figure 2(c)).

(c) Between Sexes: Males Different from Females. As examples, we may cite Rhinella icterica (Bufonidae), where males are light yellowish and females are black and white (Figure 2(d)); Leptopelis vermiculatus (Arthroleptidae), where males are green and females are brown; and most contrasting is Incilius periglenes (Bufonidae), where males are bright orange and females are black, red, and yellow.

3.2.3. Polyphenism. Polyphenism is the ability to generate different phenotypes, by color changing in this case, by the same individual. Polyphenism may be a better term to describe this phenomenon than polymorphism, which generally implies a stronger genetic element for each particular appearance [64].

Many anurans can change their dorsal coloration by rearranging their chromatophores, which involves sophisticated physiological control of skin structures. There is a continuous gradient of color change timing in anurans: the change may occur instantaneously, or may take a few minutes, hours, days, or even weeks to occur.

Some species may change their color very quickly. We placed one individual of Bokermannohyla circumdata (Hylidae) in a dark place (under tree bark) and left another individual exposed to the laboratory light. After 15 minutes, they were completely different from their initial, dark reddish-brownish coloration. The first individual (kept in the dark) was much darker, almost black, whereas the second individual (exposed) was almost white. A similar polyphenism was described for Bokermannohyla alvarengai, but in this case, the color change was studied with regard to physiological adjustments for temperature and water loss control [4].

The dorsal coloration of Scinax fuscomarginatus (Hylidae) males is yellowish during the night (during reproductive activity) and grayish or brownish during the day. This may be related to the specific site they use: during the night, they remain perched on yellowish grass vegetation [65], while during the day they can be found in dark sites, such as tree holes, under tree bark, and in the middle of clumps of grass. Conversely, this color change may be due to testosterone amount during reproductive activity (calling), as the yellowish males also have an odor which is distinct from the one they have during the daytime resting period. Additionally, individuals killed while still yellowish left a yellow tinge in the preservative liquid (formalin, alcohol). We recorded the same phenomenon for Scinax fuscovarius and S. hayii. Furthermore, some phyllomedusines can change from purplish during night activity to greenish during daytime resting. Such polyphenism was observed in Phasmahyla cochranae, P. guttata, and P. jandaia. This phenomenon can occasionally be observed in Phyllomedusa azurea, P. megacephala, and $P$. rohdei (see colored pictures in [66]).

We observed a seasonal polyphenism in Hypsiboas prasinus (Hylidae), in which a higher presence of green individuals occurred mainly in the hot, rainy season of the year, whereas a higher presence of brown individuals occurred in the cold, dry season of the year. This pattern overlaps with the frequency of green and brown leaves in the Mesophytic Semideciduos Forest where this species dwells [67]: the peak of leaf fall precedes the peak of brown morphs and the peak of leaf flushing precedes the peak of green morphs (Figure 3). Seasonal color changing has also been observed in Pseudacris regilla (Hylidae), and has been considered a response to divergent selection for crypsis in a heterogeneous, seasonally variable environment [68]. This is likely to be an explanation for the polymorphism of $H$. prasinus as well.

Polyphenism may be advantageous over polymorphism because the anuran may select a substrate and then adjust its color pattern. Polymorphic anurans may find adequate substrates to fit their general coloration, and such are not necessarily hard to find, but polyphenic species may have a wider range of substrates that they can use.

3.3. Aposematism. Aposematic coloration has also been referred to as sematic, conspicuous, or warning coloration. Aposematism is the presence of contrasting and conspicuous coloration that is generally related to the presence of skin toxins in the individuals $[7,58]$. Furthermore, it may also signalize that the anuran is dangerous or unpleasant in any other way. For example, aposematic anurans may bite, exhibit spine aggression, and/or produce loud defensive screams.

Aposematic coloration is generally bright red, orange, yellow, and/or blue on a dark (generally black), contrasting background. This aposematic coloration is most commonly widespread over the entire body, such as in species of Allobates (Aromobatidae), Ameerega and Dendrobates (Dendrobatidae), Mantella (Mantellidae), Atelopus (Bufonidae), and Brachycephalus (Brachycephalidae).

Aposematic coloration is often confined to parts that are usually concealed when the frog is in its resting posture 

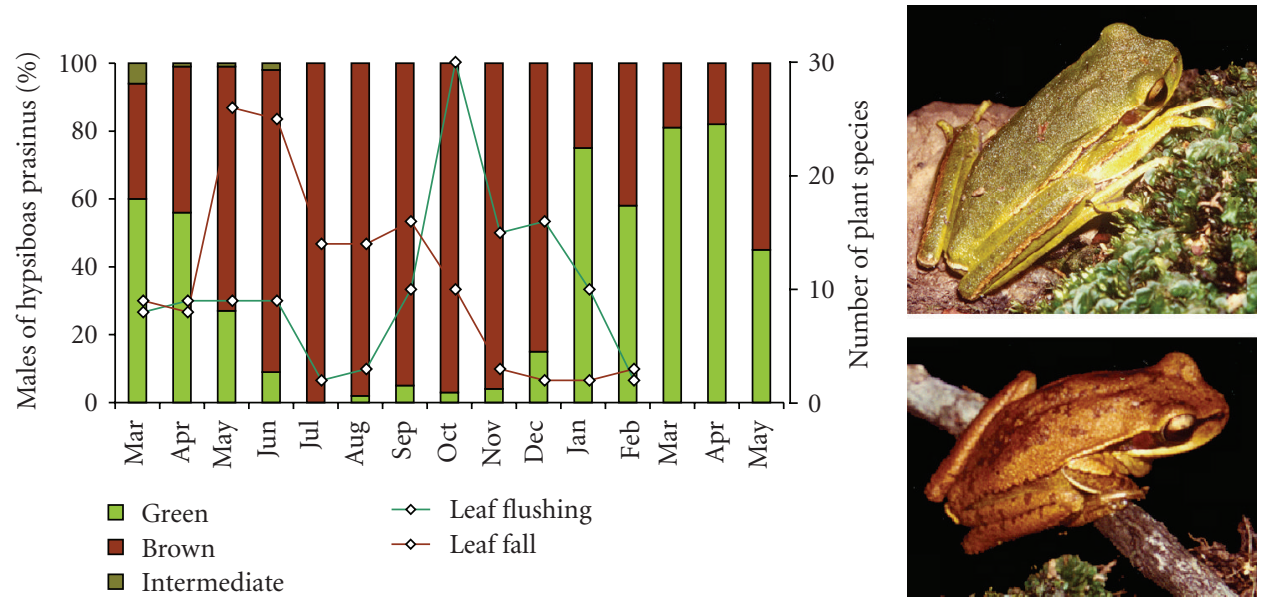

FIGURE 3: Seasonal variation (March 1988 to May 1989) in the dorsal coloration of reproductive males of Hypsiboas prasinus (Hylidae), and number of plants that exhibited leaf fall (brown lines) and leaf flushing (green lines), in Serra do Japi, Jundiaí, São Paulo, Brazil. Brown bars represent brown morphs (upper picture), green bars represent green morphs (lower picture), and olive bars represent intermediate (olive) coloration morphs. Plant phenology data were obtained from Morellato et al. [67].

(e.g., some leiuperids (Eupemphix nattereri and Physalaemus spp.), bombinatorids (Bombina spp.), hylids (Phyllomedusa spp. and Hypsiboas of the marmoratus group), bufonids (Melanophryniscus spp.), and leptodactylids (Leptodactylus of the pentadactylus group)). In this case, the bright coloration is generally present on the back of the thighs, the underside of the body, the limbs, feet, and hands, and is displayed by specific posturing such as the unken reflex [69] or body raising [65].

In species of Ceratoprhys and Hemiphractus, aposematic coloration may be present on the lips or on the tongue, respectively, which are displayed when the individuals perform the mouth-gapping display or emit defensive screams. In Phyllomedusa spp., the bright, contrasting coloration may be displayed intentionally (e.g., during foot flagging) or when the individuals walk on tree branches. The foot signaling of Atelopus zeteki, in addition to being an intraspecific communication, may be a visual display, including aposematic coloration (bright yellow contrasting with black stripes) for potential predators [70]. In Ameerega flavopicta, there seems to be a relationship between parental care and body raising [71]. Several species have a conspicuously colored belly (or other underside parts; e.g., Paratelmatobius spp., Leptodactylus pustulatus, or Melanophryniscus spp.). When facing a predator, they might not present any specific behavior to display these colors. However, they may display thanatosis (a widespread behavior in frogs) and, during handling by the predator, the anurans may be turned upside down and would thus display the aposematic coloration (Figures 2(k)-2(l)). Species of Oreophrynella, after displaying "balling behavior" while fleeing, may stop belly-side-up, exposing their bright, contrasting ventral coloration [72].

Several factors are involved in the evolution of aposematism, such as unpalatability, honest signals, relative predatorprey abundance-dependence, and kin selection (review in [73]). In anurans, aposematism has evolved multiple times (e.g., [74-76]). However, some of these authors have based their results on the hypothesis of evolutionary relationships that have been recently modified or complemented $[40,77]$. Therefore, a new overview of these evolutionary approaches to defense is needed, because their assumptions may be modified. For example, Summers and Clough [74] did their study based on the assumption that family Dendrobatidae (as considered at that time) was monophyletic, and that the toxic aposematic dendrobatids clade was also monophyletic. However, this apparent monophyly has been rejected $[75,76]$, the former dendrobatid family has been divided into two sister families (Dendrobatidae and Aromobatidae), and the toxic species are divided into several genera (e.g., Adelphobates, Allobates, Ameerega, Dendrobates, Epipedobates, Hyloxalus, Myniobates, and Oophaga) in both families [40].

Although there may be changes to the phylogenetic hypotheses, it is still possible that aposematic coloration has evolved in tandem with toxicity in anurans of the Bufonidae, Dendrobatidae, Aromobatidae, and Mantellidae families, as previously proposed (e.g., [43, 74]). "If differences among species in dietary preferences or predatory capabilities are heritable, then natural selection could act to favor brighter coloration in species that consistently have preferences for or access to prey with more or more potent toxins" [74]. Speculations apart, the most evident fact is that anuran aposematism has evolved by means of multiple convergent radiations, within the order, its families, and/or its genera (e.g., $[43,75,76,78])$.

\section{Discussion}

As we observed above, anuran coloration may provide protection against predators by providing concealment (e.g., camouflage, homotypy, and arithmetic mimicry) by alerting the predator about a possible hidden danger or unpleasant 
characteristic (aposematism), or by deceiving predators (deceptive coloration and some cases of mimicry). These strategies may act on the two first stages of predation as reviewed by Endler [79]: detection and identification.

The different types of defensive coloration presented in this study may have been selected differently throughout anuran evolution (see Table 3). Cryptic coloration (e.g., camouflage) may have been selected for by predation pressures imposed by predators upon anurans (defensive strategies), by the predatory behavior of anurans upon their prey (feeding strategies), or by both. All deceptive coloration categories (polyphenism, polymorphism, and behavioral display of colors) are directly related with predator search image. Therefore, the pressures that may have promoted them are tightly associated with the predator's vision and cerebral capability. Aposematic coloration may have multiple factors involved in its evolution. It may have evolved by means of sexual selection and/or after the acquisition of any dangerous or unpleasant defensive strategy. In the former case, in anurans, such strategies can be biting, spine aggression, defensive screams, unpalatability (in terms of bad taste), or, most commonly, noxious skin secretions. Therefore, we would not expect to find a harmless aposematic anuran, except for those involved in mimicry rings (mainly Batesian and Browerian). Indeed, as far as we know, every aposematic anuran (except for some mimics) produces harmful defenses, such as poison (e.g., some species of Mantellidae, Dendrobatidae, and Brachycephalidae: $[40,43,80]$ ), or aggressive defenses (e.g., some species of Ceratophryidae and Leptodactylidae: L. F. Toledo, I. Sazima, and C. F. B. Haddad, unpublished data). Therefore, multiple selection factors may be synergistically involved in the origin and evolution of anuran coloration.

Use of colors by anurans as a defensive strategy is a very large field of knowledge, and quite unexplored up to the present moment. Now, with this review, we attempt to organize part of our knowledge, generating at least a standardization of the nomenclature that may be applied to anuran coloration as regarding defensive strategy. Also, we added some information and insights on the relationships between predation and the defensive mechanisms of post-metamorphic anurans. From this point forward, we recommend some lines of research which may (i) complement this and other recent reviews with more observational information (which is truly lacking at present), (ii) focus on specific defensive strategies against predators and reports of predator-prey interactions, (iii) complete a broader, meta-analysis of predator-prey interactions, and (iv) advance further in the understanding of the evolution (including phylogenetic approaches) of defensive strategies and their relationships with present and past predators.

\section{Acknowledgments}

Ivan Sazima, Anne D'Heursel, Itamar Martins, Ricardo Sawaya, Rogério Bastos, and two anonymous referees made valuable comments during early versions of the manuscript. André Antunes, Cynthia Prado, Daniel Loebmann, Juliana Zina, José Pombal Jr., Luís Giasson, Olívia Araújo, and
Rodrigo Lingnau helped during field expeditions. Julián Faivovich and Patrícia Morellato helped with some references. Peter Janzen, Glenn Tattersall, André Antunes, Ricardo Sawaya, Zoltan Takacs, and Jeet Sukumaran provided the pictures of Lankanectes corrugatus, Bokermannohyla alvarengai, Eleutherodactylus guentheri, Physalaemus nattereri, Oophaga lehmanni, and Theloderma horridum, respectively. FAPESP and $\mathrm{CNPq}$ supported the Laboratório de Herpetologia, Departamento de Zoologia, UNESP, Rio Claro, São Paulo, Brazil. The authors also thank CAPES (PRODOC), FAPESP (JP proc. no. 2008/50325-5 and 2008/52847-9), Idea Wild, and Neotropical Grassland Conservancy and Fauna Pro Assessoria e Consultoria Ambiental for grants, scholarships, equipment donation, and supporting some of the expeditions.

\section{References}

[1] F. Kobelt and K. E. Linsenmair, "Adaptations of the reed frog Hyperolius viridiflavus (Amphibia, Anura, Hyperoliidae) to its arid environment. 1. The skin of Hyperolius viridiflavus nitidulus in wet and dry season conditions," Oecologia, vol. 68, pp. 533-541, 1986.

[2] R. Schmuek and K. E. Linsenmair, "Adaptations of the reed frog Hyperolius viriditlavus (Amphibia, Anura, Hyperoliidae) to its arid environment. III. Aspects of nitrogen metabolism and osmoregulation in the reed frog, Hyperolius viriditlavus taeniatus, with special reference to the role of iridophores," Oecologia, vol. 75, no. 3, pp. 354-361, 1988.

[3] R. Kaul and V. H. Shoemaker, "Control of thermoregulatory evaporation in the waterproof treefrog Chiromantis xerampelina," Journal of Comparative Physiology B, vol. 158, no. 6, pp. 643-649, 1989.

[4] G. J. Tattersall, P. C. Eterovick, and D. V. de Andrade, “Tribute to R. G. Boutilier: skin colour and body temperature changes in basking Bokermannohyla alvarengai (Bokermann 1956)," Journal of Experimental Biology, vol. 209, no. 7, pp. 1185-1196, 2006.

[5] A. Siddiqi, T. W. Cronin, E. R. Loew, M. Vorobyev, and K. Summers, "Interspecific and intraspecific views of color signals in the strawberry poison frog Dendrobates pumilio," The Journal of Experimental Biology, vol. 207, no. 14, pp. 24712485, 2004.

[6] I. Sazima and U. Caramaschi, "Descrição de Physalaemus deimaticus, sp. n., e observações sobre comportamento deimático em P. nattereri (Steindn.)-Anura, Leptodactylidae," Revista de Biologia, vol. 13, no. 1-4, pp. 91-101, 1988.

[7] M. Edmunds, Defence in Animals: A Survey of Anti-Predator Defences, Longman, New York, NY, USA, 1974.

[8] M. Martins, "Deimatic behavior in Pleurodema brachyops," Journal of Herpetology, vol. 23, no. 3, pp. 305-307, 1989.

[9] R. Symula, R. Schulte, and K. Summers, "Molecular phylogenetic evidence for a mimetic radiation in Peruvian poison frogs supports a Müllerian mimicry hypothesis," Proceedings of the Royal Society B, vol. 268, no. 1484, pp. 2415-2421, 2001.

[10] D. R. Frost, "Amphibian Species of the World 5.2, an Online Reference," American Museum of Natural History, New York, NY, USA, 2008, http://research.amnh.org/ herpetology/amphibia/index.php.

[11] G. Pasteur, "A classificatory review of mimicry systems," Annual Review of Ecology and Systematics, vol. 13, pp. 169-199, 1982. 
[12] A. Starrett, "Adaptive resemblance: a unifying concept for mimicry and crypsis," Biological Journal of the Linnean Society, vol. 48, no. 4, pp. 299-317, 1993.

[13] W. Wickler, "Mimicry and the evolution of animal communication," Nature, vol. 208, no. 5010, pp. 519-521, 1965.

[14] C. R. Darst and M. E. Cummings, "Predator learning favours mimicry of a less-toxic model in poison frogs," Nature, vol. 440, no. 7081, pp. 208-211, 2006.

[15] C. W. Myers and J. W. Daly, "Dart-poison frogs," Scienctific American, vol. 248, no. 2, pp. 120-133, 1983.

[16] C. E. Nelson and G. A. Miller, "A possible case of mimicry in frogs," Herpetological Review, vol. 3, p. 109, 1971.

[17] H.-C. Schaefer, M. Vences, and M. Veith, "Molecular phylogeny of Malagasy poison frogs, genus Mantella (Anura: Mantellidae): homoplastic evolution of colour pattern in aposematic amphibians," Organisms Diversity \& Evolution, vol. 2, no. 2, pp. 97-105, 2002.

[18] F. Andreone, "Syntopy of Mantella cowani Boulenger and Mantella madagascariensis (Grandidier) in central-eastern Madagascar, with notes on the colouration in the genus Mantella (Anura: Mantellidae)," Bollettino del Museo Regionale di Scienze Naturali, vol. 10, no. 2, pp. 421-450, 1992.

[19] J. A. Endler, "A predator's view of animal color patterns," Evolutionary Biology, vol. 11, pp. 319-364, 1987.

[20] M. D. Tuttle, L. K. Taft, and M. J. Ryan, "Acoustical location of calling frogs by Philander Opossums," Biotropica, vol. 13, no. 3, pp. 233-234, 1981.

[21] P. A. Schwalm, P. H. Starrett, and R. W. McDiarmid, "Infrared reflectance in leaf-sitting neotropical frogs," Science, vol. 196, no. 4295, pp. 1225-1227, 1977.

[22] S. B. Emerson, T. A. Cooper, and J. R. Ehleringer, "Convergence in reflectance spectra among treefrogs," Functional Ecology, vol. 4, no. 1, pp. 47-51, 1990.

[23] K. Summers, T. W. Cronin, and T. Kennedy, "Variation in spectral reflectance among populations of Dendrobates pumilio, the strawberry poison frog, in the Bocas del Toro Archipelago, Panama," Journal of Biogeography, vol. 30, no. 1, pp. 35-53, 2003.

[24] C. H. Deiques, "The development of the pit organ of Bothrops jararaca and Crotalus durissus terrificus (Serpentes,Viperidae): support for the monophyly of the subfamily Crotalinae," Acta Zoologica, vol. 83, no. 3, pp. 175-182, 2002.

[25] J. Honkavaara, M. Koivula, E. Korpimäki, H. Siitari, and J. Viitala, "Ultraviolet vision and foraging in terrestrial vertebrates," Oikos, vol. 98, no. 3, pp. 505-511, 2002.

[26] J. A. Endler and P. W. Mielke Jr., "Comparing entire colour patterns as birds see them," Biological Journal of the Linnean Society, vol. 86, no. 4, pp. 405-431, 2005.

[27] C. A. G. Cruz, "Sobre as relações intergenéricas de Phyllomedusinae da floresta atlântica (Amphibia, Anura, Hylidae)," Revista Brasileira de Biologia, vol. 50, pp. 709-726, 1990.

[28] A. H. Thayer, "The law which underlies protective coloration," The Auk, vol. 13, pp. 124-127, 1896.

[29] G. D. Ruxton, M. P. Speed, and D. J. Kelly, "What, if anything, is the adaptive function of countershading?" Animal Behaviour, vol. 68, no. 3, pp. 445-451, 2004.

[30] R. A. Kiltie, "Countershading: universally deceptive or deceptively universal," Trends in Ecology and Evolution, vol. 3, pp. 21-23, 1988.

[31] S. Braude, D. Ciszek, N. E. Berg, and N. Shefferly, "The ontogeny and distribution of countershading in colonies of the naked mole-rat (Heterocephalus glaber)," Journal of Zoology, vol. 253, no. 3, pp. 351-357, 2001.
[32] D. Osorio and M. V. Srinivasan, "Camouflage by edge enhancement in animal coloration patterns and its implications for visual mechanisms," Proceedings of the Royal Society B, vol. 244, no. 1310, pp. 81-85, 1991.

[33] B. H. Brattstrom, “The coral snake 'Mimic' problem and protective coloration," Evolution, vol. 9, no. 2, pp. 217-219, 1955.

[34] E. D. Brodie Jr. and M. S. Tumbarello, "The antipredator functions of Dendrobates auratus (Amphibia, Anura, Dendrobatidae) skin secretion in regard to a snake predator (Thamnophis)," Journal of Herpetology, vol. 12, no. 2, pp. 264265,1978 .

[35] I. C. Cuthill, M. Stevens, J. Sheppard, T. Haddocks, C. A. Párraga, and T. S. Troscianko, "Disruptive coloration and background pattern matching," Nature, vol. 434, no. 7029, pp. 72-74, 2005.

[36] J. A. Endler, "Disruptive and cryptic coloration," Proceedings of the Royal Society B, vol. 273, no. 1600, pp. 2425-2426, 2006.

[37] H. W. Bates, "Contributions to an insect fauna of the Amazon valley," Transactions of the Linnean Society of London, vol. 23, pp. 495-566, 1862.

[38] W. Wüster, C. S. E. Allum, I. B. Bjargardóttir, et al., "Do aposematism and Batesian mimicry require bright colours? A test, using European viper markings," Proceedings of the Royal Society B, vol. 271, no. 1556, pp. 2495-2499, 2004.

[39] F. H. Pough, "Mimicry of vertebrates: are the rules different?" The American Naturalists, vol. 131, supplement 1, pp. S67S102, 1988.

[40] T. Grant, D. R. Frost, J. P. Caldwell, et al., "Phylogenetic systematics of dart-poison frogs and their relatives (Amphibia: Athesphatanura: Dendrobatidae)," Bulletin of the American Museum of Natural History, vol. 299, pp. 1-262, 2006.

[41] J. W. Daly, "Thirty years of discovering arthropod alkaloids in amphibian skin," Journal of Natural Products, vol. 61, no. 1, pp. 162-172, 1998.

[42] R. A. Saporito, H. M. Garraffo, M. A. Donnelly, A. L. Edwards, J. T. Longino, and J. W. Daly, "Formicine ants: an arthropod source for the pumiliotoxin alkaloids of dendrobatid poison frogs," Proceedings of the National Academy of Sciences of the United States of America, vol. 101, no. 21, pp. 8045-8050, 2004.

[43] V. C. Clark, C. J. Raxworthy, V. Rakotomalala, P. Sierwald, and B. L. Fisher, "Convergent evolution of chemical defense in poison frogs and arthropod prey between Madagascar and the Neotropics," Proceedings of the National Academy of Sciences of the United States of America, vol. 102, no. 33, pp. 11617-11622, 2005.

[44] J. W. Daly, S. I. Secunda, H. M. Garraffo, T. F. Spande, A. Wisnieski, and J. F. Cover Jr., "An uptake system for dietary alkaloids in poison frogs (Dendrobatidae)," Toxicon, vol. 32, no. 6, pp. 657-663, 1994.

[45] J. W. Daly, W. L. Padgett, R. L. Saunders, and J. F. Cover Jr., "Absence of tetrodotoxins in a captive-raised riparian frog, Atelopus varius," Toxicon, vol. 35, no. 5, pp. 705-709, 1997.

[46] J. W. Daly, H. M. Garraffo, G. S. E. Hall, and J. F. Cover Jr., "Absence of skin alkaloids in captive-raised Madagascan mantelline frogs (Mantella) and sequestration of dietary alkaloids," Toxicon, vol. 35, no. 7, pp. 1131-1135, 1997.

[47] J. P. Caldwell, "The evolution of myrmecophagy and its correlates in poison frogs (Family Dendrobatidae)," Journal of Zoology, vol. 240, no. 1, pp. 75-101, 1996.

[48] R. A. Saporito, M. A. Donnelly, H. M. Garraffo, T. F. Spande, and J. W. Daly, "Geographic and seasonal variation in alkaloidbased chemical defenses of Dendrobates pumilio from Bocas 
del Toro, Panama," Journal of Chemical Ecology, vol. 32, no. 4, pp. 795-814, 2006.

[49] W. E. Duellman and L. Trueb, Biology of Amphibians, The Johns Hopkins University Press, London, UK, 2nd edition, 1994.

[50] A. Channing and K. Howell, "Phlyctimantis keithae (Wotwot)," Defensive Behavior Herpetological Review, vol. 34, pp. 52-53, 2003.

[51] F. Müller, "Über die Vortheile der Mimicry bei Schmetterlingen," Zoologischer Anzeiger, vol. 1, pp. 54-55, 1878.

[52] F. Müller, "Ituna and Thyridia: a remarkable case of mimicry in butterflies," Proceedings of the Entomological Society of London, vol. 1879, pp. 20-29, 1879.

[53] V. G. L. van Someren and T. H. E. Jackson, "Some comments on protective resemblance amongst African Lepidoptera (Rhopalocera)," Journal of the Lepidopterists' Society, vol. 13, pp. 121-150, 1959.

[54] M. Rothschild, "Is the buff ermine a mimic of the white ermine?" Proceedings of the Royal Entomological Society of London A, vol. 38, pp. 159-164, 1963.

[55] M. Rothschild, "The mimicrats must move with the times," Biological Journal of the Linnean Society, vol. 16, no. 1, pp. 2123, 1981.

[56] J. R. G. Turner and M. P. Speed, "How weird can mimicry get?" Evolutionary Ecology, vol. 13, no. 7-8, pp. 807-827, 1999.

[57] M. C. Dickerson, The Frog Book, Doubleday, Page, New York, NY, USA, 1906.

[58] R. C. Stebbins and N. W. Cohen, A Natural History of Amphibians, Princeton University Press, Princeton, NJ, USA, 1995.

[59] T. Caro, Antipredator Defenses in Birds and Mammals, The University of Chicago Press, London, UK, 2005.

[60] E. A. Hoffman and M. S. Blouin, "A review of colour and pattern polymorphisms in anurans," Biological Journal of the Linnean Society, vol. 70, no. 4, pp. 633-665, 2000.

[61] G. R. Bourne, "Color pattern, predator avoidance, and foraging behavior in the golden frog Colostethus beebei (Anura: Dendrobatidae)," Herpetological Review, vol. 32, no. 4, pp. 225-228, 2001.

[62] J. L. Roberts, J. L. Brown, R. Schulte, W. Arizabal, and K. Summers, "Rapid diversification of colouration among populations of a poison frog isolated on sky peninsulas in the central cordilleras of Peru," Journal of Biogeography, vol. 34, no. 3, pp. 417-426, 2006.

[63] J. W. Daly, M. A. Andriamaharavo, M. Andriantsiferana, and C. W. Myers, "Madagascan poison frogs (Mantella) and their skin alkaloids," American Museum Novitates, vol. 3177, pp. 134, 1996.

[64] R. T. Hanlon, J. W. Forsythe, and D. E. Joneschild, "Crypsis, conspicuouness, mimicry and polyphenism as antipredator defences of foraging octopuses on Indo-Pacific coral reefs, with a method of quantifying crypsis from video tapes," Biological Journal of the Linnean Society, vol. 66, no. 1, pp. 122, 1999.

[65] L. F. Toledo and C. F. B. Haddad, "Reproductive biology of Scinax fuscomarginatus (Anura, Hylidae) in south-eastern Brazil," Journal of Natural History, vol. 39, no. 32, pp. 30293037, 2005.

[66] P. C. Eterovick and I. Sazima, Amphibians from Serra do Cipó, Editora PUC Minas, Belo Horizonte, Brazil, 2004.

[67] L. P. C. Morellato, R. R. Rogrigues, H. Leitão-Filho, and C. A. Joly, "Estudo comparativo da fenologia de espécies arbóreas de floresta de altitude e floresta mesófila semidescídua na Serra do Japi, Jundiaí, São Paulo," Revista Brasileira de Biologia, vol. 12, pp. 85-98, 1989.

[68] W. H. Wente and J. B. Phillips, "Fixed green and brown color morphs and a novel color-changing morph of the pacific tree frog Hyla regilla," The American Naturalist, vol. 162, no. 4, pp. 461-473, 2003.

[69] J. Bajger, "Diversity of defensive responses in populations of fire toads (Bombina bombina and Bombina variegata)," Herpetologica, vol. 36, pp. 133-137, 1980.

[70] E. D. Lindquist and T. E. Hetherington, "Field studies on visual and acoustic signaling in the "earless" Panamanian golden frog, Atelopus zeteki," Journal of Herpetology, vol. 30, no. 3, pp. 347-354, 1996.

[71] L. F. Toledo, L. D. Guimarães, L. P. Lima, R. P. Bastos, and C. F. B. Haddad, "Notes on courtship, egg-laying site, and defensive behavior of Epipedobates flavopictus (Anura: Dendrobatidae) from two mountain ranges of central and southeastern Brazil," Phyllomedusa, vol. 3, no. 2, pp. 145-147, 2004.

[72] R. W. McDiarmid and S. Gorzula, "Aspects of the reproductive ecology and behavior of the Tepui toads, genus Oreophrynella (Anura, Bufonidae)," Copeia, vol. 2, pp. 445-451, 1989.

[73] J. Mallet and M. Joron, "Evolution of diversity in warning color and mimicry: polymorphisms, shifting balance, and speciation," Annual Review of Ecology and Systematics, vol. 30, pp. 201-233, 1999.

[74] K. Summers and M. E. Clough, "The evolution of coloration and toxicity in the poison frog family (Dendrobatidae)," Proceedings of the National Academy of Sciences of the United States of America, vol. 98, no. 11, pp. 6227-6232, 2001.

[75] J. C. Santos, L. A. Coloma, and D. C. Cannatella, "Multiple, recurring origins of aposematism and diet specialization in poison frogs," Proceedings of the National Academy of Sciences of the United States of America, vol. 100, no. 22, pp. 1279212797, 2003.

[76] M. Vences, J. Kosuch, R. Boistel, et al., "Convergent evolution of aposematic coloration in Neotropical poison frogs: a molecular phylogenetic perspective," Organisms Diversity \& Evolution, vol. 3, no. 3, pp. 215-226, 2003.

[77] D. R. Frost, T. Grant, J. Faivovich, et al., "The amphibian tree of life," Bulletin of the American Museum of Natural History, no. 297, pp. 1-291, 2006.

[78] Y. Chiari, M. Vences, D. R. Vieites, et al., "New evidence for parallel evolution of colour patterns in Malagasy poison frogs (Mantella)," Molecular Ecology, vol. 13, no. 12, pp. 3763-3774, 2004.

[79] J. A. Endler, "Defense against predators," in Predator-Prey Relationships: Perspectives and Approaches from the Study of Lower Vertebrates, M. E. Feder and G. V. Lauder, Eds., pp. 109134, The University of Chicago Press, London, UK, 1986.

[80] J. W. Daly, "The chemistry of poisons in amphibian skin," Proceedings of the National Academy of Sciences of the United States of America, vol. 92, no. 1, pp. 9-13, 1995. 

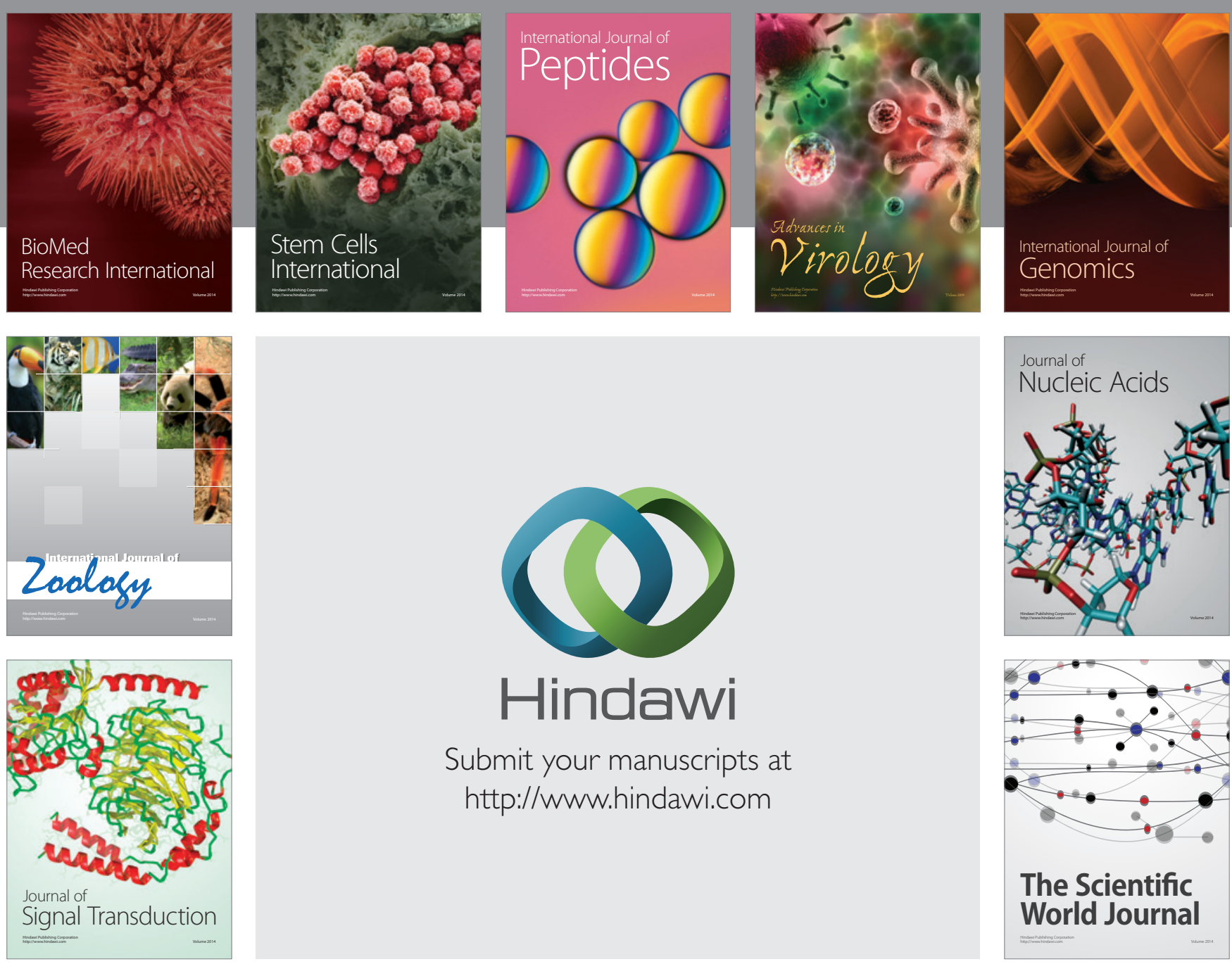

Submit your manuscripts at

http://www.hindawi.com
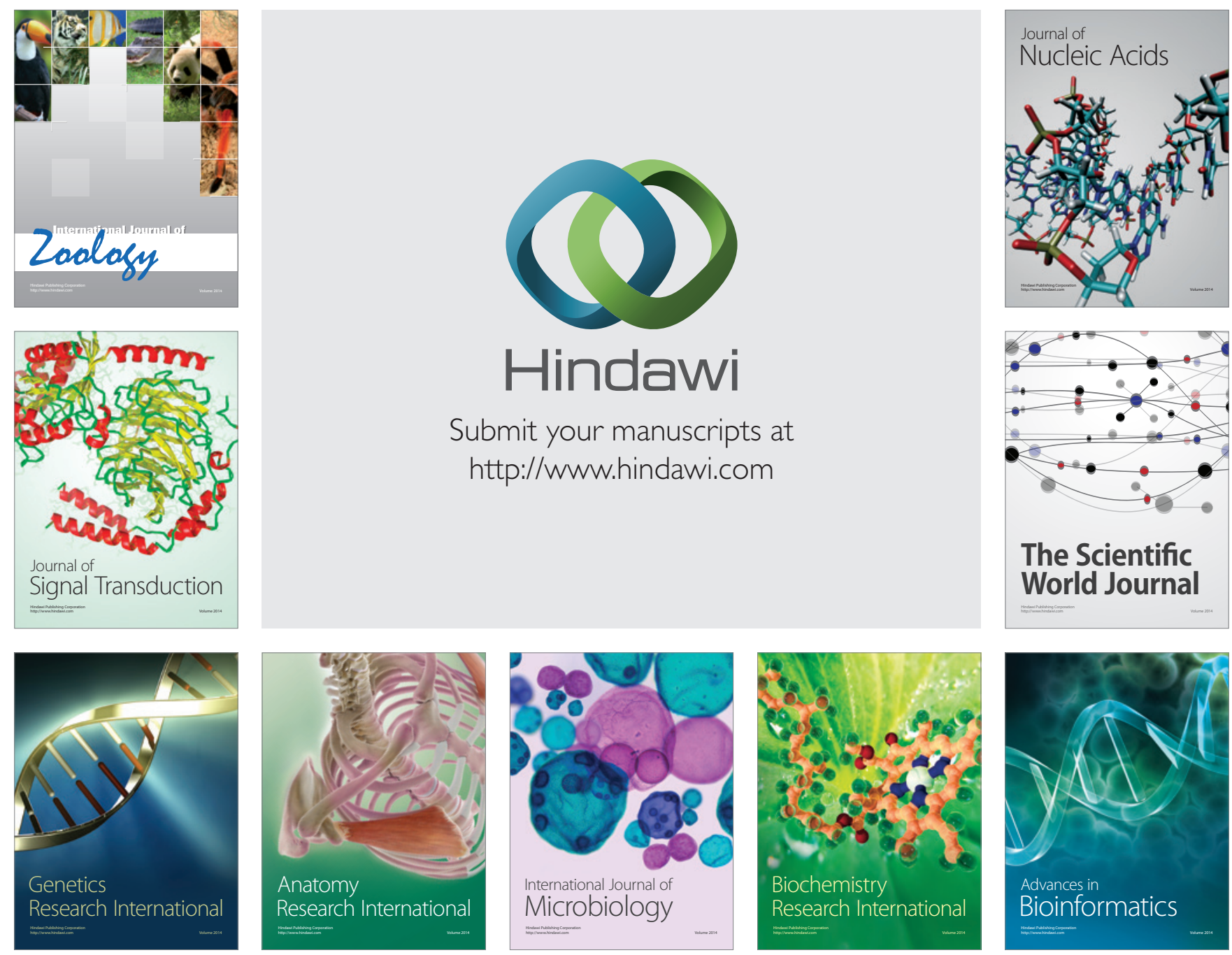

The Scientific World Journal
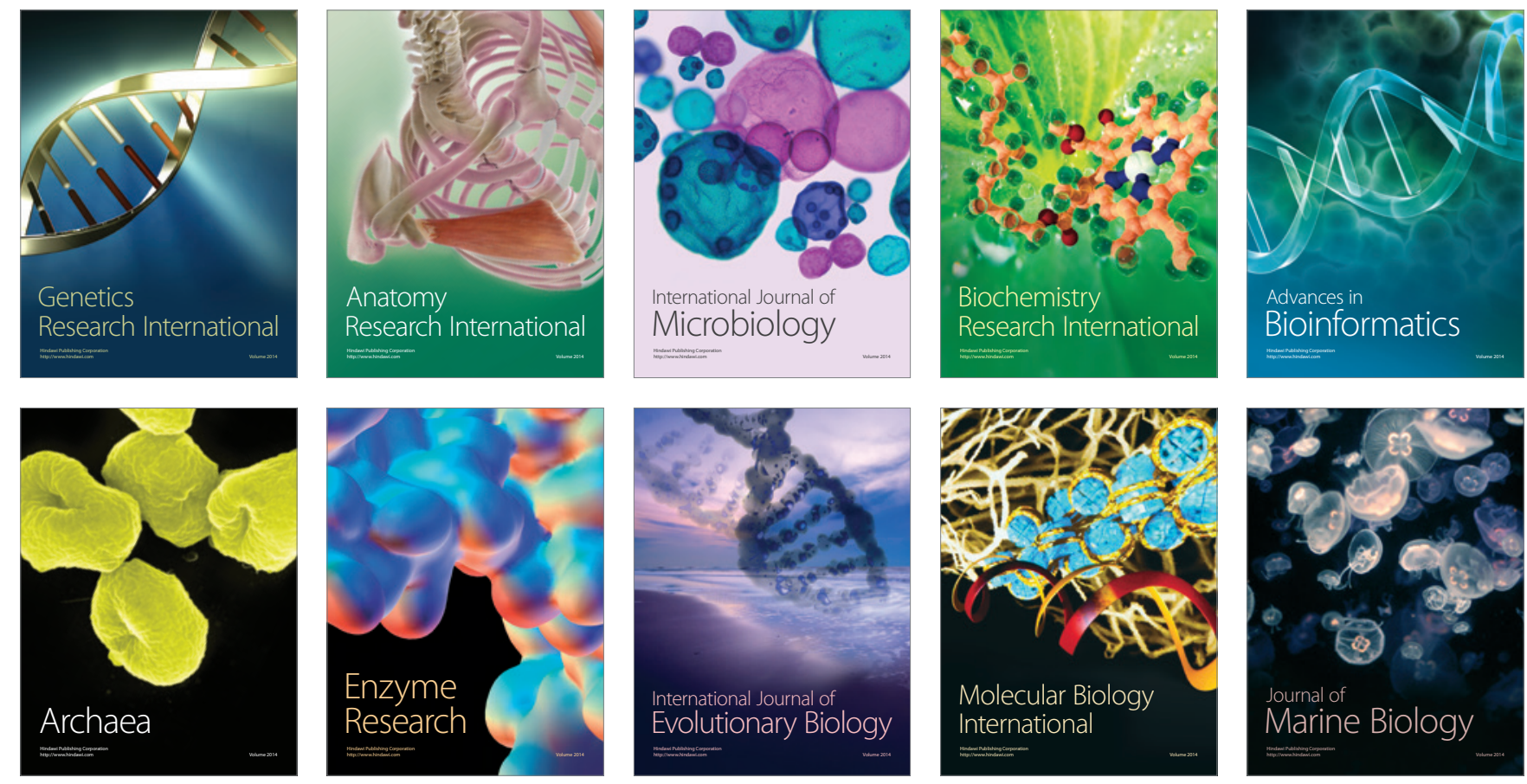